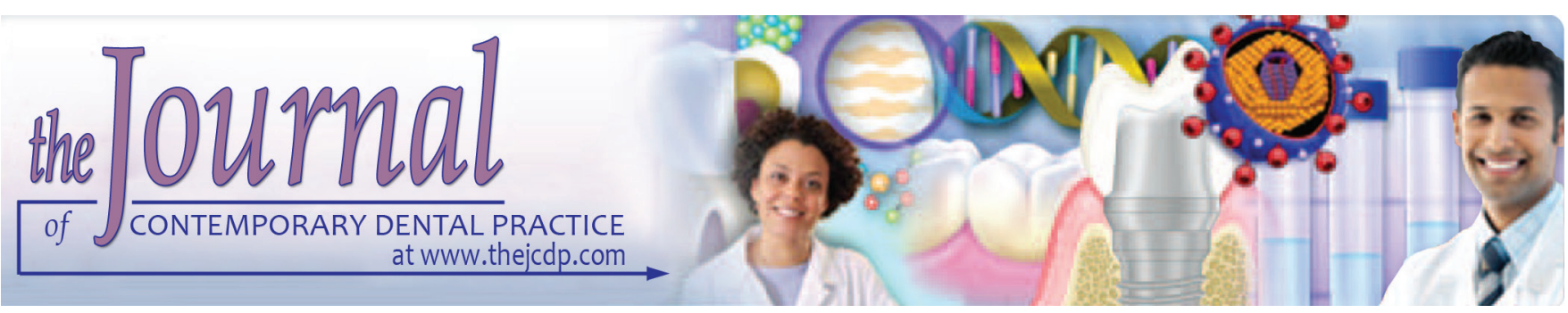

\title{
Determinants of Demand in the Public Dental Emergency Service
}

\author{
${ }^{1}$ Maria SA Matsumoto, ${ }^{2}$ Marcia AN Gatti, ${ }^{3}$ Marta HS de Conti, ${ }^{4}$ Sandra F de AP Simeão \\ ${ }^{5}$ Solange de Oliveira Braga Franzolin, ${ }^{6}$ Sara N Marta
}

\begin{abstract}
Introduction: Although dental emergencies are primarily aimed at pain relief, in practice, dental emergency services have been overwhelmed by the massive inflow of patients with less complex cases, which could be resolved at basic levels of health care. They frequently become the main gateway to the system. We investigated the determinant factors of demand at the Central Dental Emergency Unit in Bauru, São Paulo, Brazil.
\end{abstract}

Materials and methods: The questionnaire was applied to 521 users to evaluate sociodemographic profile; factors that led users to seek the service at the central dental emergency; perception of service offered.

Results: About $80.4 \%$ of users went directly to the central dental emergency, even before seeking basic health units. The reasons were difficulty to be attended (34.6\%) and incompatible time $(9.8 \%)$. To the perception of the necessity of the service, responses were problem as urgent $(78.3 \%)$ and pain was the main complaint $(69.1 \%)$. The profile we found was unmarried $(41.5 \%)$, male $(52.2 \%)$, white $(62.8 \%)$, aged 30 to $59(52.2 \%)$, incomplete basic education $(41.6 \%)$, family income up to 2 minimum wages (47.4\%), and no medical/dental plan (88.9\%).

Conclusion: It was concluded that the users of central dental emergency come from all sectors of the city, due to difficult access to basic health units; they consider their complaint urgent; and they are satisfied with the service offered.

Clinical significance: To meet the profile of the user urgency's service so that it is not overloaded with demand that can be fulfilled in basic health units.

Keywords: Demand for health services, Dental emergency, Oral health.

How to cite this article: Matsumoto MSA, Gatti MAN, de Conti MHS, de AP Simeão SF, de Oliveira Braga Franzolin S, Marta SN.

\footnotetext{
${ }^{1-6}$ Department of Dentistry, Universidade do Sagrado Coração Bauru, São Paulo, Brazil

Corresponding Author: Sara N Marta, Department of Dentistry Universidade do Sagrado Coração, Bauru, São Paulo, Brazil Phone: +551421077340, e-mail: sara@nadermarta.com.br
}

Determinants of Demand in the Public Dental Emergency Service. J Contemp Dent Pract 2017;18(2):156-161.

\section{Source of Support: Nil}

Conflict of Interest: None

\section{INTRODUCTION}

The historically adopted assistance health models in Brazil are based on hegemonic examples, with curative, commercial, and little resolute features. They represented a challenge for the implementation of the unified health system (SUS, in Portuguese) as they trailed an opposite way to universality, comprehensiveness, and health promotion. $^{1}$

The SUS is a network composed of different segments that integrate public health facilities. These facilities are responsible for ensuring the right of citizens to appointments, exams, hospitalizations and treatments, financed with funds from taxes, and contributions paid by the population. ${ }^{1,2}$

According to the Guidelines of the Oral Health National Policy (PNSB), the care model proposed aims at - among other objectives - ensuring emergency assistance in the primary care and ensuring complementary care for these cases in other health units (prompt service, emergency care, and hospital), to provide the integrality in oral health actions. The hierarchical model of health care in SUS shows that the basic health units (UBS) and family health strategies (ESF) act as a "gateway" to the system. ${ }^{3}$

While the objectives of SUS are progressively being met, dentistry has earned advances in the health area, by the Guidelines of PNSB. ${ }^{4}$ The guidelines determined that absolute priority should be given to cases of pain, infection, and suffering, which seeks universal access for assistance ${ }^{5}$ in dental urgency care - other guiding principles of actions regarding oral health care actions are also complementary to the principles of universality, comprehensiveness, and equity. 
The Ministry of Health determines that the organization of prompt service should respect the local reality, according to the evaluation of the health risk situation in the urgency appointment; the user must be oriented to continue treatment at the health unit of their ascribed area. ${ }^{3,5}$ The prompt service is a place with high passive capture, opened to anyone at all times. It is the health system's thermometer and the starting point for the evaluation of the offered services, ${ }^{5}$ which provides managers with subsidies to improve the service for the benefit of the population.

The demand for health service comes from a perspective, i.e., understood as real, i.e., the definition of a pattern or profile of consumption for health services in a place, involving elements from interrelational dynamics between the actors (the population and the health service). ${ }^{6}$

The overload on demand for dental urgent/emergency care often causes discomfort for the population and managers (and leads to continuous reflection on services), since the search for them occurs continually, in situations that mischaracterize its function, i.e., the urgency, which shows purpose deviations.

Understanding the type of population and the causes leading the user to emergency dental center (PSOC), despite having access to the basic network service, is what motivated us to investigate the determinants of demand in public dental emergency service at the PSOC of Bauru, São Paulo.

\section{MATERIALS AND METHODS}

Bauru city presents a human development index score of 0.825 , and it has a population of 344,039 inhabitants. ${ }^{7}$ Its history is linked to the presence of the important Noroeste do Brasil railway junction, built in the beginning of the 20 th century. The city's vocations are the service and the educational sector - the latter is represented by four universities and six colleges - with two universities offering the odontology course.

The city had municipal, state, and federal health services acting in isolation until the 1980s. After the creation of the National Health Reform Guidelines, the creation of SUS, and investments in the health area, the health centers network and the municipal emergency center were implemented in the city. ${ }^{8}$

In the odontology area, dental clinics were inaugurated in health centers and in the emergency dental center (PSOC), with uninterrupted service in the municipal emergency center (PSMC) building, located at the city center. Around 1993, as the city tried to seek relief for the demand of PSMC, its government inaugurated three more integrated units of ambulatory care and urgency in strategic neighborhoods.
The municipal public service had, until February 2011, 90 dental surgeons, distributed in 17 basic health units; 2 family health units; 6 reference units (Dental Specialties Center-CEO, Worker Health Reference Center-CEREST, Reference Center for Infectious Diseases - CRMI, Municipal Program for Elderly Care - PROMAI, Cancer Guidance and Prevention Section-SOPC, and Collective Health Department - DSC); treatment unit to government employees and their families at the Department of Operational Support - DAO; 11 municipal schools and 15 state schools; Municipal Schools of Integrated Childhood Education -EMEIIs; Mobile dental care; 1 clinic at the Intermunicipal Consortium of Social Promotion - CIPS. $^{9}$

The structure of these services enables medium and high complexity assistances. Emergency dental assistance is addressed on demand, 24 hours a day, every day of the week. The medical center features two equipped rooms that are used concomitantly, in peak hours, to enable better flow assistance. A medical staff of 8 dental surgeons and 6 dental assistants perform the assistances for an average of 780 patients seen in 60 days. $^{9}$

We performed the sampling plan to approach the participants - users of PSOC, aged 13 and older according to the study's objectives and the collected information. The reference population was defined to obtain a statistically representative sample, in spite of the limitations of the service's dynamics and human resources available for data collection. We performed the sampling process with a multistage technique on the reference population. ${ }^{10}$

We first conducted a stratified sampling, proportional to the number of daily visits in each period of the day: Morning, from 7 am to $1 \mathrm{pm}, 290$ patients (37.2\%); afternoon, from $1 \mathrm{pm}$ to $7 \mathrm{pm}, 262$ patients (33.6\%); and night, from $7 \mathrm{pm}$ to $7 \mathrm{am}, 228$ patients (29.2\%). To determine the number of participants in each period, we conducted a random sampling. This way, the calculation resulted in 385 individuals, according to the distribution: Morning: 143; afternoon: 129; night: 113. Data collection continued after we reached the calculated quantity, until 521 interviews, which we distributed as follows: Morning: 171; afternoon: 237; night: 113.

We performed data collection from February to May 2011, after the approval by the Research Ethics Committee of Universidade do Sagrado Coração, under protocol $n$. 207/10, according to the Resolution n. 196/1996, about researches involving humans, by the National Council of Health, Ministry of Health.

The data collection instrument was a semi-structured questionnaire, composed of 14 questions, elaborated by the researchers. The composition of the items addressed the following variables. 


\section{Sociodemographic Characteristics}

Gender, age, neighborhood of residence, marital status, race/color, personal income, household income - the current value of the minimum wage in Brazil at the time was $R \$ 545.00$ - education, and health plan coverage.

\section{Factors that motivated the Search for Service}

The previous search through UBS or directly at PSOC; event perception (consultation reason), if it was urgent or not; elapsed time from the perception of the problem until the demand for service; frequency of search for PSOC in the last 12 months and problem recurrence; vehicle used to access the service.

\section{Environment Perception}

Waiting time for service, information provided by staff, service privacy, cleaning of service areas, signaling of service areas, appearance and clothing of staff.

\section{Perception of Services}

Social service, nursing staff, transport staff, medical staff, dental staff, and reception.

Users were invited to participate in the study after screening, and preferably before clinical care, in the waiting room or in the anteroom of dental offices, so that limitations incurred by procedures would not detract data collection. Patients who agreed to contribute to the research signed the free and clear consent term (TCLE). We then excluded the polytraumatized patients.

Data were submitted for descriptive statistical analysis, and the results were presented in tables through absolute and relative distributions of frequency.

\section{RESULTS}

We present the results from the survey regarding determinants of demand in the public emergency dental center in Bauru, São Paulo, Brazil, as well as the sociodemographic profile of the 521 users -272 males $(52.2 \%)$ and 249 females (47.8\%) in Tables 1 to 5.

Users came from different neighborhoods in the city including rural areas, and some of them came from other cities. We found that 267 users $(51.2 \%)$ were married or common law partners; 254 users $(48.8 \%)$ did not have a partner (they were single, separated or divorced, and widowed). Most users, 463 (88.9\%), did not have medical or dental plan coverage.

The results from the sample distribution according to gender, age, household income, education level, race/ color, and means of transportation patients used to get to PSOC are all presented in Table 1. We see that the highest incidence age was from 30 to 59 years old, with 142 males
Table 1: User profile according to gender, age, household income, education level, race/color and means of transportation to PSOC ( $n=521)$, Bauru, São Paulo, 2011

\begin{tabular}{|c|c|c|c|}
\hline \multirow[b]{2}{*}{ Age } & \multicolumn{2}{|c|}{ Gender } & \multirow[b]{2}{*}{$\begin{array}{l}\text { Total } \\
n(\%)\end{array}$} \\
\hline & $\begin{array}{l}\text { Male } \\
(n=272) \\
n(\%)\end{array}$ & $\begin{array}{l}\text { Female } \\
(n=249) \\
n(\%)\end{array}$ & \\
\hline $13-19$ & $25(4.8)$ & $28(5.4)$ & $53(10.2)$ \\
\hline $20-29$ & $92(17.7)$ & $90(17.3)$ & $182(34.9)$ \\
\hline $30-59$ & $142(27.3)$ & $130(24.9)$ & $272(52.2)$ \\
\hline 60 and older & $13(2.5)$ & $1(0.2)$ & $14(2.7)$ \\
\hline \multicolumn{2}{|c|}{ Household income (minimum wages)* } & $\mathrm{n}(\%)$ & \\
\hline \multicolumn{2}{|c|}{ Up to 1} & $147(28.2)$ & \\
\hline \multicolumn{2}{|l|}{$1-2$} & $247(47.4)$ & \\
\hline \multicolumn{2}{|l|}{$2-5$} & $98(18.8)$ & \\
\hline \multicolumn{2}{|l|}{ Above 5} & $13(2.5)$ & \\
\hline \multicolumn{2}{|l|}{ Did not answer } & $16(3.07)$ & \\
\hline \multicolumn{4}{|l|}{ Education level } \\
\hline \multicolumn{2}{|l|}{ Unschooled } & $37(7.1)$ & \\
\hline \multicolumn{2}{|l|}{ Incomplete primary } & $217(41.6)$ & \\
\hline \multicolumn{2}{|l|}{ Complete primary } & $156(30.0)$ & \\
\hline \multicolumn{2}{|c|}{ Complete secondary education } & $105(20.2)$ & \\
\hline \multicolumn{2}{|c|}{ Complete higher education } & $6(1.1)$ & \\
\hline \multicolumn{4}{|l|}{ Race/color } \\
\hline \multicolumn{2}{|l|}{ White } & $327(62.8)$ & \\
\hline \multicolumn{2}{|l|}{ Brown } & $123(23.6)$ & \\
\hline \multicolumn{2}{|l|}{ Black } & $65(12.5)$ & \\
\hline \multicolumn{2}{|l|}{ Yellow } & $6(1.1)$ & \\
\hline \multicolumn{4}{|c|}{ Means of transportation to PSOC } \\
\hline \multicolumn{2}{|l|}{ Bus } & $274(52.6)$ & \\
\hline \multicolumn{2}{|l|}{ Own vehicle } & $171(32.8)$ & \\
\hline \multicolumn{2}{|l|}{ Ambulation } & $34(6.5)$ & \\
\hline \multicolumn{2}{|l|}{ Ambulance } & $22(4.2)$ & \\
\hline \multicolumn{2}{|c|}{ Carpooling/bike-taxi/cycling } & $20(3.9)$ & \\
\hline
\end{tabular}

*Minimum wage: $\mathrm{R} \$ 545.00$

Table 2: Distribution of frequencies of causes related to lack of attendance and search for UBS that led users to seek PSOC, Bauru, São Paulo, 2011

\begin{tabular}{|c|c|c|c|}
\hline $\begin{array}{l}\text { Causes of lack of } \\
\text { attendance at UBS }\end{array}$ & $n$ & $\begin{array}{l}\% \text { relative to the } \\
\text { total of nonat- } \\
\text { tended patients } \\
(n=104)\end{array}$ & $\begin{array}{l}\% \text { relative to } \\
\text { the total of } \\
\text { patients } \\
(n=521)\end{array}$ \\
\hline Operational causes & 56 & 53.7 & 10.7 \\
\hline Could not find vacancy & 30 & 28.7 & 5.7 \\
\hline $\begin{array}{l}\text { Problem not solved at } \\
\text { UBS }\end{array}$ & 11 & 10.4 & 2.1 \\
\hline $\begin{array}{l}\text { Waited too long and } \\
\text { gave up }\end{array}$ & 7 & 7.2 & 1.4 \\
\hline \multicolumn{4}{|c|}{ Causes of lack of demand for UBS (417-80.0\%) n (\%) } \\
\hline \multicolumn{2}{|c|}{ Difficult vacancy/delay in care } & 187 & 44.8 \\
\hline \multicolumn{2}{|l|}{ Incompatible time } & 51 & 12.2 \\
\hline \multicolumn{2}{|l|}{ Other reasons } & 45 & 10.8 \\
\hline \multicolumn{2}{|c|}{ Unaware of treatment at UBS } & 33 & 7.9 \\
\hline \multicolumn{2}{|l|}{ Always goes to PSOC } & 25 & 6.0 \\
\hline \multicolumn{2}{|c|}{$\begin{array}{l}\text { Difficult access/rural area/ } \\
\text { another city }\end{array}$} & 25 & 6.0 \\
\hline \multicolumn{2}{|l|}{ Pain } & 23 & 5.5 \\
\hline \multicolumn{2}{|l|}{ Lack of dentist at UBS } & 19 & 4.6 \\
\hline \multicolumn{2}{|l|}{ Extraction } & 9 & 2.2 \\
\hline
\end{tabular}


Table 3: Distribution of frequencies of the user's perception on the condition of urgency or no urgency, Bauru, São Paulo, 2011

\begin{tabular}{ll}
\hline User perception of the condition of urgency & $n(\%)$ \\
\hline Urgency & $408(78.3)$ \\
No urgency & $113(21.7)$ \\
Causes for urgency $(\mathrm{n}=408-78.3 \%)$ & \\
Pain & $347(85.0)$ \\
Other reasons & $35(8.6)$ \\
Edema & $14(3.5)$ \\
Fractured tooth/restoration loss & $12(2.90)$ \\
\hline
\end{tabular}

Table 5: Distribution of relative frequencies of users regarding the perception of the service provided by PSOC, Bauru, São Paulo, 2011

\begin{tabular}{llllll}
\hline Perception & Excellent & Good & Regular & Bad & Terrible \\
\hline $\begin{array}{l}\text { Waiting time for } \\
\begin{array}{l}\text { attendance } \\
\text { Information provided }\end{array}\end{array}$ & 5.5 & 47.4 & 24.6 & 15.0 & 7.5 \\
$\begin{array}{l}\text { Service facilities } \\
\text { Site cleanup }\end{array}$ & 8.0 & 83.7 & 8.6 & 1.7 & 0.6 \\
$\begin{array}{l}\text { Signs of service } \\
\text { areas }\end{array}$ & 11.3 & 76.0 & 11.3 & 0.8 & 0.6 \\
$\begin{array}{l}\text { Appearance and } \\
\text { clothing of staff }\end{array}$ & 11.7 & 75.5 & 11.1 & 1.9 & 0.4 \\
\hline
\end{tabular}

(27.3\%) and 130 females (24.9\%). Predominant household income (247 users $-47.4 \%$ ) was of 1 to 2 minimum wages; instruction level was elementary school, with 373 $(71.6 \%)$ individuals, and the most frequent answer was "Incomplete" (217 users - 41.6\%); most users answered "white" for race (327 users $-62.8 \%$ ). Most interviewees went to PSOC by public transportation - bus (274 users $-52.6 \%$ ), or with their own vehicles (171 users $-32.8 \%$ ).

About 104 (20.0\%) participants looked for the UBSs that were closer to their homes, before going to PSOC, and the others (419-80.0\%) headed directly to the central emergency unit. The causes that led patients not to UBSs are described in Table 2; most of them (56-53.7\%) pointed operational causes - human resources and infrastructure; the second highest frequency (30-28.7\%) was not finding vacancy, and $10.4 \%$ (11) did not have their problem solved at the UBSs, because it involved specialties, such as periodontics, endodontics, and others. The 419 patients who did not look for care at the UBS and went straight to PSOC reported that their main reasons were difficulty to find a vacancy and service delay (187-44.8\%), 12.2\% (51) indicated incompatible time; other reasons, such as proximity to work and health plan service were highlighted by 45 $(10.8 \%)$ individuals. Nine $(2.2 \%)$ users pointed out the need for tooth extraction and knew that the procedure was not performed at the UBS.

When asked about the perception of their emergency condition (Table 3), 408 (78.3\%) users identified their status as urgent, with pain as the most prevalent cause
Table 4: Frequency distribution of consultations, elapsed time from the beginning of the problem until the search for assistance and recurrence of consultations at the PSOC in the last 12 months, Bauru, São Paulo, 2011

\begin{tabular}{ll}
\hline Number of consultations $(n=521)$ & $n(\%)$ \\
\hline 1 & $354(68.0)$ \\
$2-6$ & $158(30.3)$ \\
$7-12$ & $9(1.7)$ \\
Elapsed time until the search for assistance & \\
$(\mathrm{n}=521)$ & \\
Less than 2 days & $131(25.2)$ \\
$1-2$ weeks & $210(40.3)$ \\
More than 15 days & $61(11.7)$ \\
More than 1 month & $61(11.7)$ \\
More than 6 months & $58(11.1)$ \\
Recurrence at PSOC $(\mathrm{n}=167-32.1 \%)$ & \\
Same complaint & $62(37.1)$ \\
Another complaint & $105(62.9)$ \\
\hline
\end{tabular}

(347-85.0\%). Whereas 35 (8.6\%) individuals highlighted other reasons: Endodontics, tooth mobility, extraction, and other items that were classified as purpose deviations (extractions with prosthetic purposes, definitive restorations, and routine evaluations of oral conditions).

Table 4 presents the results on number of visits, elapsed time from the beginning of the problem until the demand for care, and recurrence of appointments at the PSOC in the last 12 months. Also, 354 individuals $(68.0 \%)$ pointed out that only 1 appointment was necessary to solve the problem; 131 (25.2\%) people looked for the service $<2$ days after perceiving the discomfort, while other $210(40.3 \%)$ waited up to 2 weeks to search for professional care. Out of 521 users, 167 (32.1\%) were recurrent patients, and 62 (37.1\%) of them had the same complaint.

In Table 5, we can observe the frequencies that are related to the users' perception of the service at PSOC. The concept "Good" was most frequent in the sample for all questions. We noticed that only the item "Waiting time for attendance" presented frequency of $22.5 \%$ with concepts "Bad" and "Terrible."

About $57.9 \%$ of users returned to PSOC and attributed the concepts "Excellent" or "Good" for the Dental Staff service.

\section{DISCUSSION}

During the implementation process of SUS, managers face limitations for changing the model of assistance based on the principles of universality, integrality, and equity that are expressed in the constitution. ${ }^{11}$ Due to the expansion of quantity and quality of health services and the lack of absorption of demands that still exist at UBSs, public dental emergency services should ensure the access of users in cases of pain, offering the first assistance, to promote better biological conditions to the patient, as well as more agile routing for the treatment. ${ }^{11}$ Managers 
should also be a link between the various levels of the complexity of health care, and observe the aspects regarding humanization and reception of users, to build a care thread, reorganize the demand and ensure the integrality of provided services. ${ }^{12}$

As we evaluated the sociodemographic characteristics, with respect to the neighborhoods from which the sample participants came, we observed dispersed frequencies - likely a result of the PSOC being located in the city's central area. Some users came from other neighborhoods where ESF units are found. We think that this may have happened because their residences were excluded from the program's coverage area, or the high demand for local units led the users to look for care at PSOC. ${ }^{13,14}$

Another fact that shows the majority of users live in the outskirts of the city is how they came to the PSOC (Table 1), i.e., by bus (52.6\%) and their own vehicles (32.8\%).

The highest frequency of age was between 30 and 59 years old, which is in accordance with the results of several studies. ${ }^{15-17}$

The high demand of young adults for urgency emergency services was also described in studies in the cities of Araraquara (São Paulo) and Recife (Pernambuco). The occurrence was attributed to the lack of service availability as these people were not anymore attended at their schools. ${ }^{15,18}$ The research indicated a decrease of demand for attendance starting from the age 40 , due to a significant loss of teeth over the years, conditioned to the lack of access to preventive and conservative dental procedures. ${ }^{17}$

Some studies on dental urgency services ${ }^{15,17,18}$ showed a higher frequency of women. This differs from this study's results, in which the predominance of males was $52.2 \%$.

Most users had incomplete primary school, $41.6 \%$ (Table 1), and household income of up to two minimum wages $-75.6 \%$ (Table 1 ). This shows that schooling and income strongly relate to the use of emergency public services. This was also observed in other studies, ${ }^{15,19}$ which show that most users did not reach high school and had an income of up to two minimum wages.

Data pointed by PNAD 2010 show that the highest concentration of people who have health plans was from higher family income groups, ${ }^{17,20}$ which is understandable since only $11.1 \%$ of participants who searched for PSOC had medical or dental plans.

Regarding the conditioning factors of service use, we can observe that the main reasons for the users who sought for the UBS not finding service are operational causes $(53.7 \%)$ and lack of vacancy (28.7\%) (Table 2$)$. In addition to that, difficult vacancy/delay in care (44.8\%) and incompatible time (12.2\%) were the main causes among those who did not seek UBSs before heading to PSOC. This action possibly shows that the users' dissatisfaction with frustrated visits to outpatient clinics makes it harder to establish bonds between the clinic and the users, which leads the latter to look for a solution where they know they will be attended - even if the solution is palliative. This is consistent with results pointed in studies conducted in the states of Mato Grosso and Paraíba, as well as others. ${ }^{13,14,16,21,22}$

To alleviate the overload at PSOC and to improve UBS services, the scheduling systematics for dental appointments should be questioned, in spite of some positive aspects. Because of the current scheduling process, local users who should receive priority care, due to the locality criterion, ended up being harmed. Another important result is that $7.9 \%$ of users reported not knowing about dental care service at UBSs (Table 2), which suggests the need for public information campaigns about the availability of health public services.

The results presented in Table 3 show that most users who sought emergency dental care had the adequate perception of the service's purpose: $78.3 \%$ justified their presence at the PSOC with the most frequent complaint of pain $(85.0 \%)$. Even for the patients who reported their problem as not urgent, the pain was the main reason for the demand. This does not mischaracterize the objective of urgency service, as it was also described in other studies, with very similar percentages (83.4 and $80.3 \%$ ). ${ }^{18,23}$

Table 4 shows the elapsed time from the first symptoms until the search for care. We found a predominance of 1 to 2 weeks ( $40.3 \%)$. Although there are variations of the event among the studied researches, ${ }^{17,24}$ in most cases dental intervention is delayed and the seek for it occurs only when the patient can no longer bear the pain. ${ }^{24}$ Such behavior may indicate the existence of barriers for the search of relief from suffering.

Regarding the frequency of need for urgency department, we verified that $68 \%$ users sought the PSOC only once in 12 months (Table 4), which is contrary to the evaluations of other studies that reported abusive use and users looking for ease of access and convenience. ${ }^{15-17}$

The concepts attributed to users regarding the perception of services at PSOC were mostly distributed between "Excellent" and "Good," although we notice that the aspect that mostly displeased participants was waiting time - with concepts "Regular" - 24.6\%, "Bad" - 15\%, and "Terrible" $-7.5 \%$. ${ }^{18,19}$

Overloading in urgency/emergency care services often causes discomfort for population and managers and takes to continuous reflection about the need for expanding the services to reduce waiting time. However, users continuously seek these services for attendances that mischaracterize their function, namely urgency/ emergency, which indicates purpose deviations. ${ }^{4,16}$

With the obtained results, we could verify that although most cases are related to the work purpose of 
PSOC, the number of users who look for service before even trying the basic network is still a major issue. Although with not alarming percentages for a city of the size of Bauru, the distorted demand already represents an overload in service with the consequent increased waiting time for those who really need urgency/emergency treatment.

Educational campaigns should be increased and enlighten the population on the purpose of the services provided by PSOC and the extension/localization of the available basic network of ambulatory assistance, to improve the quality and efficiency of services of the whole municipal network.

Understanding the type of population and the causes that lead people to look for assistance at PSOC, even if they have access to the basic network services, is what motivated us to investigate the determinants of demand in public dental emergency services at the Emergency Dental Center in Bauru, São Paulo, Brazil.

\section{CONCLUSION}

Our approach on the determinants of demand in public dental emergency service at the Emergency Dental Center in Bauru, São Paulo, Brazil led us to find that most of the attended users had no medical or dental plan. These users were between 30 and 59 years, white race/color, with incomplete primary education and had a family income of up to two minimum wages (based on the national minimum wage), regardless of gender. It was shown that most treated patients did not look for the UBSs in their neighborhoods because of the difficulty in finding vacancies.

The reasons for the users' demand at the PSOC were in accordance with the purpose of the service; their main complaint was pain, and the recurrence of consultations did not characterize the formation of a clientele group. The service received positive evaluations from the users.

\section{REFERENCES}

1. Pires FS, Botazzo C. Technological organization in oral health in SUS: an archeology of national policy for oral health. Saude Soc 2015 Mar;24(1):273-284.

2. Brazil. Ministy of Health. Law 8080; 1990. Avaliable from: http://www.planalto.gov.br/ccivil_03/leis/L8080.htm

3. Brazil. Ministry of Health. Secretariat for Health Care. Department of Basic Attention. National Coordination of Oral Health. Oral Health Policy Guidelines - Brazil. Brasília: Ministry of Health; 2004.

4. Antunes JL, Narvai PC. Dental health policies in Brazil and their impact on health inequalities. Rev Saude Publica 2010 Apr;44(2):360-365.

5. Brazil. Ministry of Health. Secretariat for Health Care. Department of Specialized Attention. Medical Regulation of ER/Ministry of Health, Ministry of Health, Department of Specialized Attention. Brasilia: Publishing House of the Ministry of Health; 2006.
6. Pinheiro R, Mattos RA. Senses of completeness and attention in health care. Rio de Janeiro: UERJ, IMS, ABRASCO; 2006. p. 184

7. The Brazilian Institute of Geography and Statistics-IBGE. Synopsis of the Census 2010. November/2010 [cited 2011 Feb 28]. Available from: http://www.ibge.gov.br/home/.

8. Capistrano FD. Health for all: a challenge to the municipality. The response of Bauru. 2nd ed. São Paulo: HUCITEC; 1998.

9. Municipal Secretariat of Health of Bauru; 2011. Avaliable from: http://www.bauru.sp.gov.br/saude/servicos_saude.aspx.

10. ZarJH. Biostatistical analysis. 4th ed. University of Michigan, NJ: Prentice-Hall; 1999. 663 p.

11. Brazil. Constitution. Constitution of the Federative Republic of Brazil: Promulgated on 5 October 1988. Contains the Constitutional Amendments Later. Brasilia, DF: Senate; 1988.

12. Brazil. Ministry of Health, (MS). Secretariat for Health Care. Department of Basic Attention. National Coordination of Oral Health. Guidelines of the National Oral Health Policy. Brasilia: Ministry of Health (MS); 2004.

13. Almeida GC, Ferreira MA. Oral health in the context of the Family Health Program: Preventive practices targeting individual and public health. Cad Saude Publica 2008 Sep;24(9):2131-2140.

14. Souza TM, Roncalli AG. Oral health in the Brazilian Family Health Program: a health care model evaluation. Cad Saude Publica 2007 Nov;23(11):2727-2739.

15. Abbud R, Ferreira LA, Campos AG, Zanin KE. Clinical care: a study of the services offered in ten years. Rev APCD 2002;56(4):271-275.

16. Ferreira OJ, Damante JH. Emergency dental service: epidemiological and administrative aspects. RPG 1998;5(1):31-38.

17. Tortamano IP, Leopoldino VD, Borsatti MA, Penha SS, Buscariolo IA, Costa CG, Rocha RG. Aspectos epidemiológicos e sociodemográficos do Setor de Urgências da Faculdade de Odontologia da Universidade de São Paulo. RPG Rev Pós Grad 2007;13(4):299-306.

18. Carnut L, Figueiredo N, Goes PS. Assessment of the level of satisfaction of users of dental emergencies in the city of Recife. UFES Rev Odontol 2008;10(3):10-15.

19. Faccin D, Sebold R, Carcereri DL. Work process in oral health: seeking different looks to understand and transform the reality. Cien Saude Colet 2010 Jun;15(Suppl 1):1643-1652.

20. 2010 PNAD-Ministry of Planning, Budget and Management, The Brazilian Institute of Geography and Statistics-IBGE. National Research for Sample of Domiciles. An overview of health in Brazil: access and use of the services, health conditions and risk factors and health protection. Rio de Janeiro: IBGE; 2010 [cited 2015 Oct 12]. Available from: http:/ / www. bvsms.saude.gov.br/bvs/publicacoes/pnad_panorama_ saude_brasil.pdf.

21. Fonseca DA, Mialhe FL, Ambrosano GM, Pereira AC, Meneghim MC. Influence of the organization of primary care and the socio-demographic characteristics of the population on the demand for municipal emergency dental care. Cien Saude Colet 2014 Jan;19(1):269-277.

22. Marta SN, Gatti MAN, De Vitta A, Simeão SFAP, De Conti MHS, Saes SO, Palma R, Carvalho RS. Family health program under the user's perspective. Salusvita 2011;30(3):159-177.

23. Martins EP, Oliveira OR, Bezerra SR, Dourado AT. Epidemiological study of dental emergencies of the FOP/ UPE. RFO 2014 Dec;19(3):316-322.

24. Lacerda JT, Simionato EM, Peres KG, Peres MA, Traebert J, Marcenes W. Dental pain as the reason for visiting a dentist in a Brazilian adult population. Rev Saude Publica 2004 Jun;38(3):453-458. 